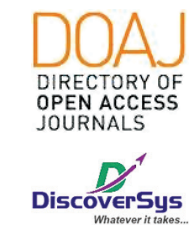

Published by DiscoverSys

\section{Pengaruh suhu penyimpanan terhadap kedalaman pengerasan dan kekuatan resin komposit}

\author{
Kholidina Imanda Harahap*
}

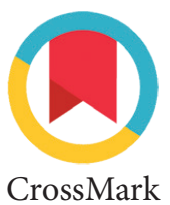

CrossMark

\title{
ABSTRACT
}

Introduction: Temperature plays a role in polymerization process of composite resin. Depth of cure is often used as a marker of polymerization adequacy in composite resins. Adequate polymerization will increase the mechanical properties of composite resin. The aim of this study was to evaluate the effect of storage temperature on depth of cure and compressive strength of composite resin.

Method: Samples were made from nanofiller composite resin (Filtek Z350 XT,3M,ESPE,USA) after the materials were stored at $4^{\circ} \mathrm{C}$ and $24^{\circ} \mathrm{C}$ for two weeks. Twenty samples of nanofiller composite resins for each test group were prepared using metal mould with $6 \mathrm{~mm}$ in diameter and $4 \mathrm{~mm}$ thick. Samples were cured under visible blue light for 20 second. The polymerized composite resin was measured for determining the depth of cure. Compressive strength of samples was tested by using Universal Testing Machine.

Result: The results showed that depth of cure value of $24^{\circ} \mathrm{C}(3.90 \pm$ $0.07 \mathrm{~mm})$ was higher than $4^{\circ} \mathrm{C}(3.83 \pm 0.17 \mathrm{~mm})$ and compressive strength of $24^{\circ} \mathrm{C}(35.20 \pm 4.63 \mathrm{MPa})$ was higher than $4^{\circ} \mathrm{C}(26.47 \pm$ $3.13 \mathrm{MPa}$ ). Statistical analysis showed that depth of cure were no siginificant differences $(p>0.05)$ but in compressive strength were significant differences between test groups $(p<0.05)$.

Conclusion: Storage temperature can affect the depth of cure and compressive strength of composite resin, although no significant difference on the depth of cure.

Keywords : storage temperature, depth of cure, compressive strength, composite resin

Cite This Article: Harahap, K.I. 2018. Pengaruh suhu penyimpanan terhadap kedalaman pengerasan dan kekuatan resin komposit. Intisari Sains Medis 9(3): 30-34. DOI: 10.1556/ism.v9i3.275

\section{ABSTRAK}

Latar Belakang: Suhu berperan pada proses polimerisasi resin komposit. Kedalaman pengerasan sering digunakan sebagai penanda kecukupan polimerisasi resin komposit. Polimerisasi yang adekuat akan meningkatkan sifat mekanis resin komposit. Tujuan penelitian ini adalah untuk mengevaluasi pengaruh suhu penyimpanan yang berbeda terhadap kedalaman pengerasan dan kekuatan tekan resin komposit. Metode: Sampel dibuat dari resin komposit partikel nano (Filtek Z350 XT,3M,ESPE,USA) setelah bahan disimpan pada suhu $24^{\circ} \mathrm{C}$ dan $4^{\circ} \mathrm{C}$ selama dua minggu. Dua puluh sampel untuk tiap kelompok uji dibuat dengan menggunakan cetakan besi berdiameter $6 \mathrm{~mm}$ dan ketebalan $4 \mathrm{~mm}$. Sampel dikeraskan dengan sinar tampak biru selama 20 detik. Sampel yang sudah mengeras diukur untuk mendapatkan data kedalaman pengerasan. Kekuatan tekan diuji mengunakan alat Universal Testing Machine.

Hasil: Hasil menunjukkan nilai kedalaman pengerasan pada suhu $24^{\circ} \mathrm{C}$ $(3,90 \pm 0,07 \mathrm{~mm})$ lebih tinggi dibandingkan $4^{\circ} \mathrm{C}(3,83 \pm 0,17 \mathrm{~mm})$. Nilai kekuatan tekan pada suhu $24^{\circ} \mathrm{C}(35,20 \pm 4,63 \mathrm{MPa})$ lebih tinggi dibandingkan $4^{\circ} \mathrm{C}(26,47 \pm 3,13 \mathrm{MPa})$. Tidak terdapat perbedaan yang signifikan pada kedalaman pengerasan $(p>0,05)$ tetapi terdapat perbedaan kekuatan tekan yang signifikan di antara dua kelompok uji $(p<0,05)$.

Simpulan: Suhu penyimpanan dapat mempengaruhi kedalaman pengerasan dan kekuatan tekan resin komposit walaupun pengaruhnya tidak signifikan terhadap kedalaman pengerasan.
Department of Dental Material and Technology of Faculty of Dentistry, Universitas Sumatera Utara

\section{*Corresponding:}

Kholidina Imanda Harahap, Department of Dental Material and Technology of Faculty of Dentistry, Universitas Sumatera Utara kholidinaimandaharahap@gmail. com

Diterima: 2018-05-22 Disetujui: 2018-07-28 Diterbitkan: 2018-12-1
Kata kunci: suhu penyimpanan, kedalaman pengerasan, kekuatan tekan, resin komposit

Cite Pasal Ini: Harahap, K.I. 2018. Pengaruh suhu penyimpanan terhadap kedalaman pengerasan dan kekuatan resin komposit. Intisari Sains Medis 9(3): 30-34. DOI: 10.1556/ism.v9i3.275

\section{PENDAHULUAN}

Resin komposit merupakan bahan restorasi yang sering digunakan dokter gigi. Kemampuannya dalam meniru warna gigi adalah kelebihan bahan ini dan merupakan alasan pemilihan bahan ini pada restorasi estetis. Selain itu, resin komposit memiliki sifat mekanis dan fisis yang baik sehingga dapat digunakan dalam jangka waktu lama. ${ }^{1,2}$ Resin komposit terus dikembangkan untuk menghasilkan bahan dengan sifat mekanis dan optis yang lebih baik. Seperti resin komposit partikel nano, yang memiliki kekuatan mekanis seperti resin komposit partikel mikrohibrid akan tetapi pada saat yang sama dapat mempertahankan kehalusan permukaannya. $^{3}$ 
Kekuatan tekan pada bahan restorasi dianggap sebagai sifat yang paling penting sebagai indikator keberhasilan restorasi jangka panjang. Karena kekuatan tekan yang baik sangat diperlukan untuk menahan tekanan pengunyahan dan parafungsional. ${ }^{2}$ Kekuatan tekan yang dimiliki oleh bahan restorasi harus memiliki nilai yang setara dengan kekuatan tekan dari gigi asli. Kekuatan tekan pada resin komposit dipengaruhi oleh dua faktor, yaitu ukuran bahan pengisi dan polimerisasi. ${ }^{4,5}$

Polimerisasi resin komposit berhubungan dengan kedalaman pengerasan yang terjadi. Kedalaman pengerasan tergantung pada kedalaman penetrasi cahaya sinar tampak biru yang menembus resin komposit. Intensitas cahaya pada permukaan bahan sangat penting untuk meningkatkan polimerisasi resin komposit. Semakin dalam penetrasi sinar ke dalam resin komposit akan meningkatkan polimerisasi. ${ }^{6}$

Polimerisasi resin komposit dipengaruhi oleh beberapa faktor, yaitu komposisi, warna, translusensi, jenis alat sinar, jarak penyinaran, waktu penyinaran dan suhu resin komposit. Suhu dapat mempengaruhi polimerisasi resin komposit. ${ }^{7}$ Penelitian sebelunya menunjukkan suhu berpengaruh terhadap polimerisasi resin komposit. Awliya (2007) menyatakan bahwa suhu yang lebih tinggi dapat meningkatkan polimerisasi resin komposit. ${ }^{8}$ Suhu yang tinggi dapat memberikan energi yang lebih banyak bagi pergerakan monomer dan radikal bebas untuk membentuk rantai polimer. ${ }^{9}$ Suhu juga dapat mempengaruhi viskositas resin komposit. Karena suhu panas akan menurunkan viskositas dan meningkatkan pergerakan monomer. ${ }^{10}$

Untuk memperpanjang waktu simpan, produsen resin komposit menginstruksikan untuk menyimpan bahan tersebut pada suhu $23^{\circ}-4^{\circ} \mathrm{C}$ jika tidak digunakan. Instruksi ini telah dilakukan oleh dokter gigi dengan menyimpan resin komposit di dalam lemari pendingin. Karena suhu yang fluktuatif dapat mempengaruhi kestabilan komponen resin komposit. Dengan menyimpannya pada suhu yang disarankan dapat mempertahankan kestabilan komposisinya. Akan tetapi, masih ada dokter gigi yang menyimpan resin komposit pada suhu kamar yang tidak terkendali.

Berdasarkan paparan di atas, penelitian ini bertujuan untuk mengevaluasi pengaruh suhu penyimpanan terhadap kedalaman pengerasan dan kekuatan tekan resin komposit.

\section{BAHAN DAN METODE}

\section{Pembuatan sampel}

Sebelum digunakan, resin komposit partikel nano (Filtek Z 350 XT,3M ESPE, St.Paul, MN, USA) disimpan pada dua suhu yang berbeda yaitu $24^{\circ} \mathrm{C}$ dan $4^{\circ} \mathrm{C}$ selama dua minggu. Jumlah sampel untuk masing-masing pengujian adalah 40 buah yang dibagi menjadi dua kelompok perlakuan yaitu kelompok yang disimpan pada suhu $24^{\circ} \mathrm{C}$ (kelompok 1) dan $4^{\circ} \mathrm{C}$ (kelompok 2).

\section{Pengukuran Kedalaman Pengerasan}

Resin komposit partikel nano dimasukkan ke dalam cetakan logam dengan diameter $6 \mathrm{~mm}$ dan tinggi $4 \mathrm{~mm}$ yang sudah diolesi dengan minyak silikon dan dialasi dengan cellophane strip. Kemudian cellophane strip dan glass slide diletakkan pada permukaan bahan selama 1 menit lalu glass slide diangkat. Bahan dikeraskan dengan sinar tampak biru yang keluar dari alat sinar pengeras (Litex 680A, Dentamerica,AS) selama 20 detik dengan jarak penyinaran $0 \mathrm{~mm}$. Sampel dikeluarkan dari cetakan dan dirapikan. Setelah sampel mengeras, bagian sampel yang tidak mengeras dibuang menggunakan spatula plastik. Kemudian bagian sampel yang tersisa diukur menggunakan kaliper digital dengan akurasi $\pm 0.1 \mathrm{~mm}$. Besarnya angka yang tertera dicatat sebagai nilai kedalaman pengerasan sampel.

\section{Uji Kekuatan Tekan}

Untuk uji kekuatan tekan, resin komposit partikel nano dimasukkan ke dalam cetakan dari logam yang berdiameter $4 \mathrm{~mm}$ dan tinggi $6 \mathrm{~mm}$ yang sudah diolesi minyak silikon dan dialasi dengan cellophane strip. Kemudian cellophane strip dan glass slide diletakkan pada permukaan bahan selama 1 menit, lalu glass slide diangkat. Bahan dikeraskan dengan sinar tampak biru yang keluar dari alat sinar pengeras (Litex 680A, Dentamerica, AS) selama 20 detik dengan jarak penyinaran $0 \mathrm{~mm}$ pada permukaan atas dan bawah. Sampel yang telah mengeras dikeluarkan dari dalam cetakan dan disimpan di dalam wadah kedap sinar selama 24 jam. Kemudian dilakukan uji kekuatan tekan menggunakan Universal Testing Machine (Servopulser, Jepang). Beban seberat $200 \mathrm{kgf}$ dengan kecepatan $0.5 \mathrm{~mm} / \mathrm{min}$ ditekankan pada sampel perlahan-lahan sampai sampel patah. Nilai yang tertera pada layar dimasukkan ke dalam rumus $\sigma c(\mathrm{MPa})=\mathrm{F} / \mathrm{A}$, dimana $\sigma c=$ kekuatan tekan $(\mathrm{MPa}), \mathrm{F}=$ gaya maksimal $\left(\mathrm{kgms}^{-2}\right), \mathrm{A}=$ luas penampang $\left(\mathrm{mm}^{2}\right)$.

\section{Analisis Statistik}

Distribusi normalitas data diuji menggunakan uji normalitas Saphiro Wilk dengan tingkat kemaknaan $p>0.05$. Jika data berdistribusi normal akan dilanjutkan dengan uji $\mathrm{T}$ tak berpasangan untuk melihat perbedaan kedalaman pengerasan dan kekuatan tekan antar kelompok perlakuan dan tingkat kemaknaan $p<0.05$. Apabila data tidak 
berdistribusi normal, data akan diuji dengan uji Mann-Whitney

\section{HASIL}

Dari penelitian ini diperoleh bahwa nilai kedalaman pengerasan sampel pada kelompok 1 lebih tinggi dari kelompok 2 seperti yang terlihat pada gambar 1. Nilai kedalaman pengerasan pada kelompok 1 adalah 3,90 $\pm 0,07 \mathrm{~mm}$ sedangkan pada kelompok 2 adalah 3,83 $\pm 0,17 \mathrm{~mm}$. Berdasarkan hasil uji normalitas, diperoleh bahwa data tidak berdistribusi normal $(p<0,05)$ dan kemudian uji statistik dilanjutkan dengan uji non-parametrik Mann-Whitney. Hasil uji Mann-Whitney menunjukkan tidak ada perbedaan kedalaman pengerasan yang signifikan diantara kelompok perlakuan dengan nilai signifikansi $p=0,39(p>0,05)$.

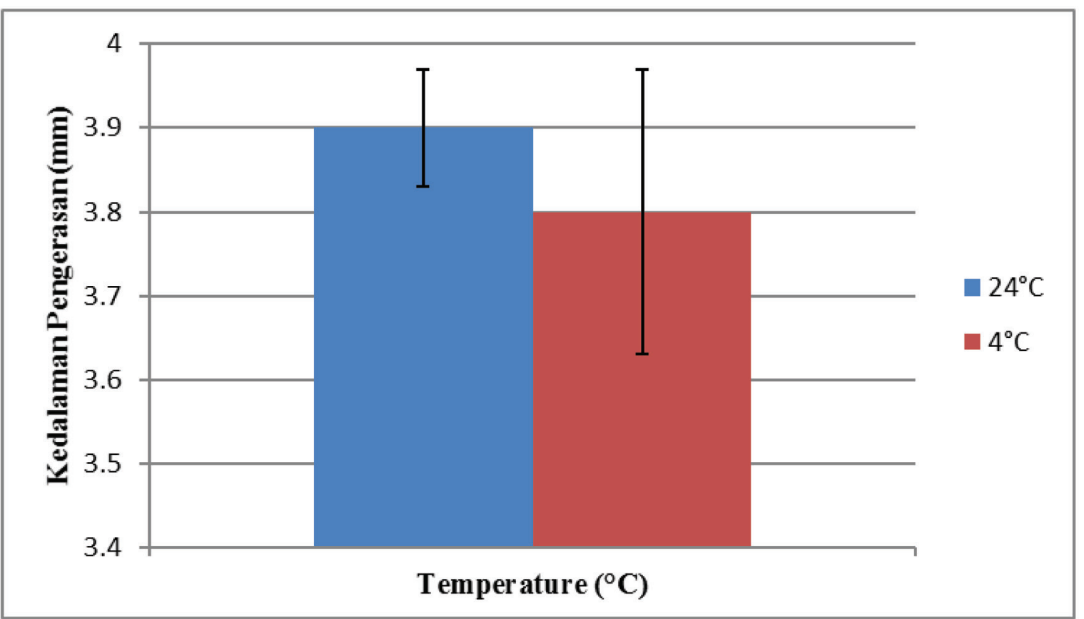

Gambar 1 Grafik nilai kedalaman pengerasan resin komposit nanofiller dengan suhu penyimpanan yang berbeda

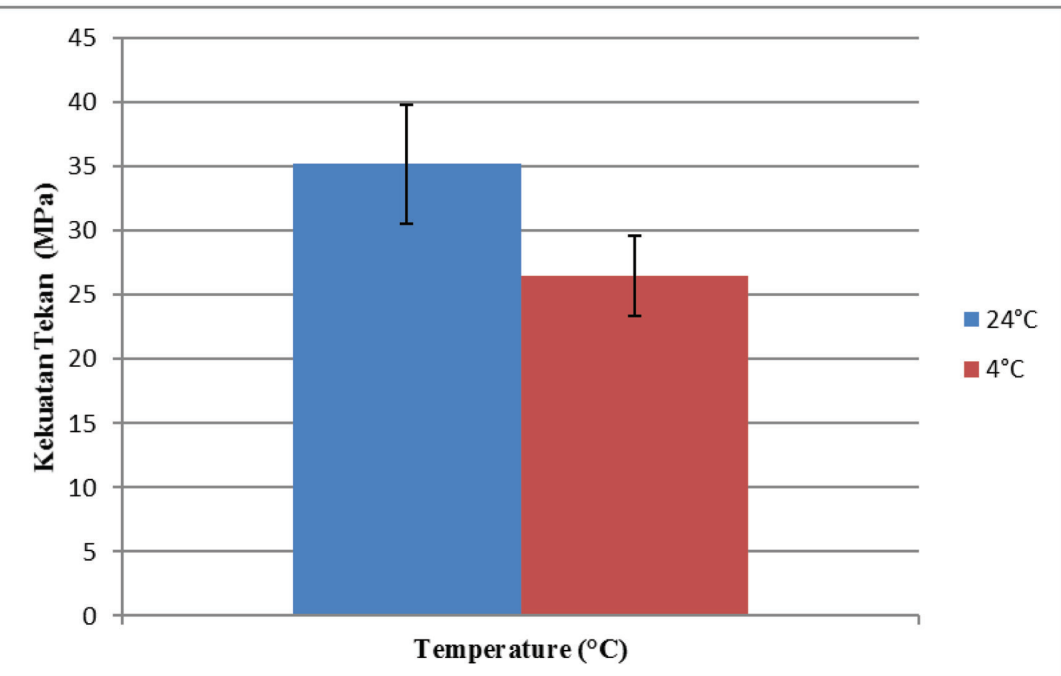

Gambar 2 Grafik kekuatan tekan resin komposit nanofiller dengan suhu penyimpanan yang berbeda
Pada gambar 2 dapat dilihat bahwa nilai kekuatan tekan pada kelompok 1 lebih tinggi dibandingkan pada kelompok 2. Nilai kekuatan tekan pada kelompok 1 adalah $35,20 \pm 4,63 \mathrm{MPa}$ dan pada kelompok 2 adalah 26,47 $\pm 3,13 \mathrm{MPa}$. Berdasarkan hasil uji normalitas diperoleh data berdistribusi normal $(p>0,05)$. Pengujian dilanjutkan dengan uji $\mathrm{T}$ tak berpasangan dan memperoleh hasil ada perbedaan kekuatan tekan yang signifikan antara kelompok perlakuan dengan nilai signifikansi $p<$ $0,001(p<0,05)$.

\section{PEMBAHASAN}

Polimerisasi resin komposit yang adekuat tergantung dari kedalaman pengerasan yang terjadi. Kedalaman pengerasan adalah jarak dari permukaan ke dasar resin komposit yang mengalami pengerasan. Kedalaman pengerasan dipengaruhi oleh penetrasi sinar, panjang sinar, penyebaran sinar, dan iradiasi. ${ }^{711}$

Dari hasil penelitian yang diperoleh dapat diketahui bahwa suhu penyimpanan resin komposit sebelum dikeraskan dapat mempengaruhi kedalaman pengerasan walaupun tidak signifikan $(p>$ 0,05 ). Resin komposit yang disimpan pada suhu $24^{\circ} \mathrm{C}$ memiliki kedalaman pengerasan yang lebih tinggi dibandingkan pada suhu $4^{\circ} \mathrm{C}$. Pada penelitian ini, resin komposit yang disimpan pada suhu $4^{\circ} \mathrm{C}$ digunakan segera setelah dikeluarkan dari dalam kulkas.

Suhu memainkan peranan penting dalam proses polimerisasi resin komposit. Suhu dapat mempengaruhi viskositas resin komposit. Suhu yang tinggi dapat menurunkan viskositas resin komposit sedangkan suhu yang rendah dapat meningkatkannya. Viskositas pada resin komposit dikaitkan dengan kecepatan pergerakan monomer-monomer pada matriks resin. Pergerakan monomer pada saat proses polimerisasi menentukan besarnya konversi monomer membentuk rantai polimer. Pada suhu rendah, kecepatan pergerakan monomer akan menurun yang berdampak pada singkatnya proses polimerisasi. Hal ini disebabkan karena mobilitas rantai polimer berkurang dan mempercepat fase terminasi. Singkatnya waktu polimerisasi akan menurunkan derajat konversi resin komposit. ${ }^{10,12}$ Berdasarkan penelitian, derajat konversi dipengaruhi oleh kandungan resin organik, karena karakteristik seperti reaktifitas dan mobilitas monomer berkaitan dengan pembentukan rantai polimer. ${ }^{13}$

Semakin tinggi suhu resin komposit akan memicu pergerakan monomer lebih cepat untuk berpolimerisasi. Sehingga waktu yang diperlukan pada tahap induksi bisa lebih singkat. Hal ini disebabkan karena inisiator menjadi lebih berenergi untuk memulai perpindahan energi kepada 
molekul monomer untuk bereaksi. Jika pada tahap induksi tidak menghabiskan banyak waktu, maka pada tahap propagasi dan terminasi dapat memiliki waktu yang cukup bagi molekul monomer untuk saling berikatan membentuk rantai polimer. ${ }^{14}$

Beberapa penelitian mengatakan bahwa untuk meningkatkan derajat konversi resin komposit bisa dengan meningkatkan suhu dengan memanaskan resin komposit pada suatu alat pemanas khusus. Menurut Dionysopoulus (2016), ${ }^{15}$ pemanasan pada suhu $54^{\circ} \mathrm{C}$ dapat meningkatkan kekerasan resin komposit. Dengan adanya peningkatan suhu, viskositas resin komposit yang mengandung radikal bebas dan monomer akan menurun. Sehingga monomer yang berpolimerisasi bisa lebih banyak dan ikatan silang yang terbentuk lebih kuat dan lengkap. Akibatnya, derajat konversi resin komposit meningkat dan kekerasan permukaan juga akan meningkat. ${ }^{15}$ Menurut Munoz (2008) memanaskan resin komposit dengan alat pemanas resin komposit dapat meningkatkan kecepatan konversi monomer, kedalaman pengerasan dan kekerasan. ${ }^{6}$

Selain dengan menggunakan alat, resin komposit yang dikeluarkan dari dalam kulkas bisa dibiarkan selama beberapa menit pada suhu ruang. Faria-eSilva (2010) menyatakan bahwa resin komposit yang disimpan pada suhu $4^{\circ} \mathrm{C}$ harus dikeluarkan dari dalam kulkas minimal 20 menit sebelum digunakan. ${ }^{16} \mathrm{~K}$ Harahap (2017) ${ }^{17}$ menyatakan bahwa diperlukan waktu beberapa saat sebelum menggunakan resin komposit yang disimpan di dalam kulkas. Resin komposit yang dibiarkan pada suhu kamar selama 60 menit setelah dikeluarkan dari dalam kulkas memiliki kedalaman pengerasan yang lebih tinggi dibandingkan dengan resin komposit yang langsung digunakan. Bahkan nilai kedalaman pengerasannya hampir sama dengan kedalaman pengerasan resin komposit yang disimpan pada suhu kamar. ${ }^{17}$

Polimerisasi terbaik akan meningkatkan sifat fisik dan mekanis resin komposit. Suatu bahan restorasi akan bertahan lama di dalam mulut jika memiliki kekuatan yang sempurna. Kekuatan tekan pada resin komposit harus baik agar mampu menahan tekanan yang diterima pada saat pengunyahan. Kekuatan tekan dipengaruhi oleh derajat konversi monomer membentuk polimer. Seperti yang telah disebutkan di atas, bahwa suhu penyimpanan mempengaruhi derajat konversi monomer. ${ }^{2,5}$

Pada penelitian ini dapat dilihat bahwa resin komposit yang disimpan pada suhu $24^{\circ} \mathrm{C}$ sebelum penyinaran, memiliki kekuatan tekan yang lebih tinggi dibandingkan dengan yang disimpan pada suhu $4^{\circ} \mathrm{C}$. Perbedaan kekuatan tekan yang diperoleh pada penelitian ini signifikan. Suhu penyimpanan yang rendah dapat menurunkan pergerakan monomer sehingga menurunkan derajat konversi monomer menjadi polimer. Berkurangnya derajat konversi akan menurunkan kekuatan tekan resin komposit.

Beberapa penelitian terdahulu telah menyimpulkan bahwa suhu dapat mempengaruhi beberapa sifat mekanis resin komposit. Pada penelitian Osternack (2009) menunjukkan adanya perbedaan kekerasan permukaan yang signifikan antara resin komposit yang disimpan pada suhu $24^{\circ} \mathrm{C}$ dengan $4^{\circ} \mathrm{C}$. Dimana kekerasan permukaan lebih rendah pada resin komposit yang disimpan pada suhu $4^{\circ} \mathrm{C} .{ }^{10}$ Daronch (2006) menyatakan bahwa terdapat korelasi yang kuat antara suhu dan konversi monomer. ${ }^{18} \mathrm{Hal}$ ini disebabkan karena adanya peningkatan suhu sehingga akan menurunkan viskositas resin komposit dan meningkatkan mobilitas radikal, yang menyebabkan tahap konversi berlangsung lebih cepat dan resin komposit menjadi lebih keras. ${ }^{14}$

Saran yang diberikan produsen untuk menyimpan resin komposit pada suhu $4^{\circ} \mathrm{C}$ bertujuan untuk menjaga kestabilan komposisi resin komposit. Akan tetapi berdasarkan hasil penelitian yang diperoleh, suhu dapat mempengaruhi polimerisasi yang berakibat terhadap kekuatan resin komposit. Penyimpanan pada suhu rendah dapat menurunkan kekuatan tekan dan kedalaman pengerasan resin komposit.

\section{SIMPULAN}

Berdasarkan hasil penelitian yang diperoleh, dapat disimpulkan bahwa ada pengaruh suhu penyimpanan terhadap kedalaman pengerasan dan kekuatan tekan resin komposit. Resin komposit yang disimpan pada suhu tinggi memiliki kedalaman pengerasan dan kekuatan tekan yang lebih tinggi. Sedangkan resin komposit yang disimpan pada suhu rendah memiliki kedalaman pengerasan dan kekuatan tekan yang lebih rendah.

\section{DAFTAR PUSTAKA}

1. Koh R, Neiva G, Dennison J, Yaman P. Finishing Systems on The Final Surface Roughness of Composite. J Cont Dent Prac. 2008;9(2):1-8.

2. Annusavice KJ. Phillip's Science of Dental Material. 11th ed. Missouri: Elsevier; 2007.

3. Powers JM, Sakaguchi R. Craig's Restorative Dental Material. 13th ed. St.Louis: Elsevier; 2012.

4. Banava S, Salehyar S. In Vitro Comparative Study of Compressive Strength of Different Types of Composite Resins in Different Periods of Time. Iranian Journal of Pharmaceutical Sciences. 2008;4(1):69-74.

5. AlShaafi M. Factors affecting polymerization of resin-based composites: A literature riview. The Saudi Dental Journal. 2017;29:48-58.

6. Munoz C, Bond P, Munoz J, Tan D. Effect of Pre-Heating on Depth of Cure and Surface Hardness of LightPolymerized Resin Composites. American Journal of Dentistry. 2008;21(4):215-22. 
7. Anusavice KJ. Phillips science of dental materials. $12^{\text {th }}$ ed. St.Louis: Saunders; 2013.

8. Awliya W. The influence of temperature on The Efficacy of Polymerization of Composite Resin. J Cont Dent Pract. 2007;8(6):9-16.

9. Howard B. Relationships between Conversion, Temperature and Optical Properties during Composite Photopolymerization. Acta Biomater. 2010;6(6):2053-59.

10. Osternack F, Caldas D, Rached RSV. Impact of Refrigeration on The Surface Hardness of Hybrid and Microfilled Composite Resin. Braz Dent J. 2009;20(1):42-7.

11. Mahn E. Clinical criteria for the successful curing of composite materials. Rev Clin Periodoncial Implatol Rehabil Oral. 2013;6(3):148-53.

12. Van Noort R. Introduction to Dental Materials. 4th ed. Philadelphia: Mosby Elsevier; 2013.

13. Gaglianone LA, Lima AF, de Araujo LSN, Cavalcanti AN Marchi GM. Influence of different shades and LED irradiance on the degree of conversion of composite resins. Braz Oral Res. 2012;26(2):165-9.

14. Torres R, Caneppele T, Borges B, Torres A. Influence of Pre-Cure Temperature in Vickers Microhardness of resin Composite. IJCD. 2011;2(3):41-5.
15. Dionysopoulos D, Tolidis K, Gerasimou P. Bulk Fill Composite Resins. A Novelty in Resin-Based Restorative Materials. ARC Journal of Dental Science. 2016;1(2):1-3.

16. Faria-e-Silva A. Piva E,Moraes R. Time-Dependent Effect of Refrigeration on Viscosity and Conversion Kinetics of Dental Adhesive Resins. European Journal of Dentistry. 2010;4:150-55.

17. Harahap K, Yudhit A, Sari F. Effect of Bench Time Polymerization on Depth of Cure of Dental Composite Resin. In IOP Conference Series: Materials Science and Engineering: Proceedings of Innovation in Polymer Science and Technology 2016,Nov 7-10, Medan, Indonesia: IOP Publishing Ltd; 2017. p.1-6.

18. Daronch M, Rueggeberg F, DeGoes M, Giudici R. Polymerization Kinetics of Pre-Heated Composite. J Dent Res. 2006;85:38-43.

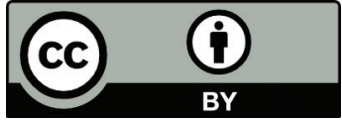

This work is licensed under a Creative Commons Attribution 